\title{
Análise de estruturas sanduíche: parâmetros de projeto
}

\author{
Analysis of sandwich structures: design parameters
}

\begin{abstract}
Debora Pierini Gagliardo Nilson Tadeu Mascia

Debora Pierini Gagliardo Departamento de Engenharia Civil Centro Universitário Adventista de São Paulo Estrada Municipal Pastor Walter Fazenda Lagoa Engenheiro Coelho - SP - Brasil Caixa-Postal 11 CEP 13165-000

Tel.: (19) 3858-9000 R.: 9059 E-mail:

debora.pierini@unasp.edu.br

\section{Resumo}

A

s estruturas sanduíche têm despertado grande interesse e já estão bastante difundidas em diversos segmentos industriais, sendo suas principais utilizações nas indústrias aeroespacial, militar e civil. Este fato se deve à sua propriedade de combinar alta rigidez à flexão e baixo peso, resultando em uma estrutura muito eficiente. Neste trabalho foram analisadas as estruturas tipo sanduíche, considerando seu comportamento mecânico e possíveis aplicações na construção civil. É apresentada uma rotina para elaboração de projetos para a construção civil utilizando as estruturas sanduíche, com ênfase em estruturas planas, tais como vigas e placas. Emprega-se também uma ferramenta, planilha eletrônica, para analisar e avaliar a aplicação de diversos materiais de construção em estruturas tipo sanduíche.
\end{abstract}

Nilson Tadeu Mascia Departamento de Estruturas

Faculdade de Engenharia Civil,Arquitetura e Urbanismo

Universidade Estadual de Campinas

Av. Albert Einstein, 951, Barão Geraldo

Campinas - SP - Brasil Caixa-Postal 6021 CDP $13083-970$

Tel.: (19) 3521-2318 E-mail: nilson@fec.unicamp.br

Recebido em 01/05/10 Aceito em 25/09/10
Palavras-chave: Estruturas sanduíche. Ortotropia. Critérios de falha. Vigas. Placas.

\section{Abstract}

Sandwich structures have aroused much interest and are already widespread in different industrial sectors, especially in aerospace, military and construction. This is due to their characteristic of being able to combine high bending rigidity and low weight, resulting in a very efficient structure. In this paper, sandwich structures were analyzed considering their mechanical behavior and possible applications in the building industry. A routine is presented for the development of designs for the construction industry, using sandwich structures, emphasizing flat structures, such as beams and plates. A spreadsheet is also used to analyze and evaluate the application of various building materials in sandwich structures.

Keywords: Sandwich structures. Orthotropy. Failure criteria. Beams. Plates. 


\section{Introdução}

De acordo com Callister (2002), um compósito estrutural é composto tanto de materiais homogêneos como de materiais heterogêneos ou compósitos, cujas propriedades dependem não somente das propriedades dos materiais constituintes, mas também do projeto geométrico dos elementos estruturais.

Uma estrutura do tipo sanduíche consiste basicamente de duas placas (faces finas) de um material resistente, intercaladas por uma camada de outro material, em geral de baixa densidade e de resistência inferior à das placas. A resistência desse conjunto a flexão, em certas condições, pode ser muito maior que a de uma placa maciça, constituída do mesmo material e de mesma densidade que as duas faces do sanduíche.

O sistema construtivo que se utiliza de painéis sanduíche proporciona boas características de resistência e de isolamento térmico e acústico, podendo ser uma alternativa vantajosa em relação a outros tipos tradicionais de construção, como os que utilizam paredes de alvenaria ou sistemas préfabricados de concreto, por exemplo.

Os objetivos principais deste trabalho foram estudar e analisar as estruturas do tipo sanduíche, já aplicadas no Brasil e em outros países, considerando seu comportamento mecânico e possíveis aplicações na construção civil, apresentando como principais contribuições a sistematização do cálculo de estruturas sanduíche e a organização de dados. Com a sistematização do cálculo, torna-se factível a criação de rotinas que facilitem a comparação de diversas combinações face/núcleo, chegando, assim, a uma solução ótima de forma concisa e segura.

\section{Estruturas sanduíche}

Projetos de estruturas do tipo sanduíche têm sido concebidos e adotados como um meio de gerar estruturas resistentes, duráveis e de baixo peso. Essas estruturas são especialmente eficientes na transferência de cargas de flexão e compressão. O uso delas vem se expandindo devido a sua capacidade de combinar alta rigidez a flexão e baixo peso.

A importância da diminuição do peso de estruturas foi primeiramente reconhecida pelas indústrias aeroespaciais, pois nelas o projeto estrutural do avião é controlado mais pelo peso que pelo custo. Em contrapartida, nas indústrias civil, mecânica e automotiva, os custos são as considerações iniciais, apesar de que o peso do sistema afeta os custos e o desempenho. Outro fator importante nessas considerações é que a crescente falta de matéria-prima e o rápido esgotamento das fontes de energia convencional aumentam a necessidade de estruturas leves, eficientes e de baixo custo.

Estruturas sanduíche são constituídas por duas ou mais camadas de materiais diferentes, as quais são admitidas, em geral, perfeitamente aderidas, e a combinação delas faz com que o elemento, como um todo, ganhe em termos de eficiência estrutural. A principal característica é a obtenção de elementos com maior rigidez, conseguida com o afastamento das faces resistentes. Pode-se conseguir ainda estruturas mais leves, dependendo do material a ser utilizado.

De acordo com Tita (2007), essas estruturas constituem um tipo especial de laminado. As faces têm a função de suportar as tensões normais de tração, compressão ou cisalhamento associadas à flexão. $\mathrm{O}$ núcleo, por sua vez, deve manter o afastamento das faces, ser suficientemente rígido na direção perpendicular a elas, a fim de evitar o esmagamento, e sua rigidez ao cisalhamento transversal deve ser grande o suficiente para garantir que o conjunto funcione.

\section{Aplicações de estruturas sanduíche}

Da mesma forma como ocorreu com os materiais compostos em geral, a aplicação dos elementos do tipo sanduíche começou a se expandir em direção à indústria da construção civil a partir da década de 1990.

$\mathrm{Na}$ área da construção civil a utilização de estruturas sanduíche ainda é recente. No entanto, já existem componentes no mercado com características bem desenvolvidas, utilizados para divisórias, paredes, pisos, forros, mezaninos, passarelas e lajes, entre outras aplicações. Esses componentes podem ter atributos de interesse, como resistência a elevadas cargas distribuídas, capacidade de vencer grandes vãos, resistência à umidade e intempéries, excelente isolamento térmico e acústico, alta resistência a impactos, resistência ao fogo e respeito ao meio ambiente. Para que todas as características e propriedades mencionadas anteriormente sejam atingidas, tornase necessária a seleção dos materiais que comporão essas estruturas. A Figura 1 apresenta algumas possibilidades de núcleos para um painel sanduíche.

Analisando-se essa figura, tornam-se claras a possibilidade e a necessidade de utilização de diversos materiais (faces, núcleos, adesivos) em sua fabricação. Para cada finalidade existem 
opções de materiais com propriedades mecânicas distintas. Na fase de cálculo há a necessidade de conhecer as propriedades dos materiais que serão utilizados. Para obtê-las, deve-se realizar ensaios ou, em caso de materiais disponíveis no mercado industrializado, é possível obter suas propriedades junto aos fabricantes. O Quadro 1 apresenta algumas propriedades de materiais comumente utilizados como núcleos em estruturas sanduíche.

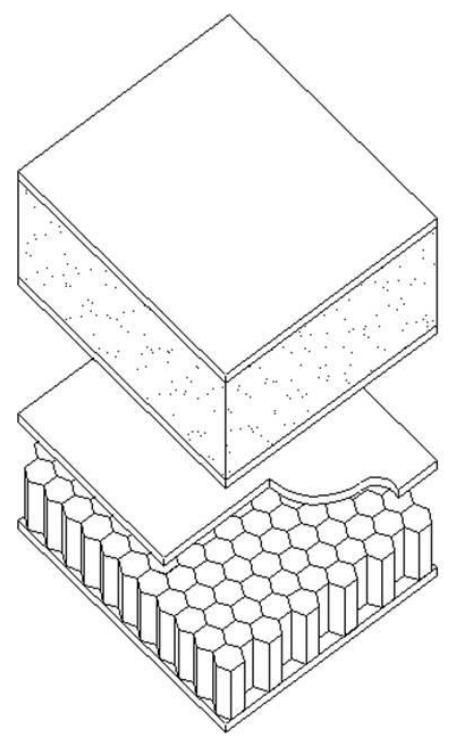

(a)

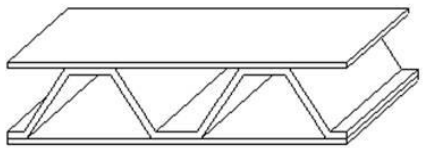

(c)

(b)

Fonte: Allen (1969).

Figura 1 - Painéis sanduíche com recheio: (a) polimérico, (b) colmeia, (c) corrugado

\begin{tabular}{c|c|c|c|c|c}
\hline Propriedades & PVC & Fenólicos & Poliuretano & $\begin{array}{c}\text { Poliestireno } \\
\text { (isopor) }\end{array}$ & Balsa \\
\hline Densidade $\rho, \mathrm{kg} / \mathrm{m}^{3}$ & 65 & 55 & 70 & 40 & 92 \\
\hline Módulo de elasticidade $E_{T}$ & 55 & 7 & 19 & 11 & 2.450 \\
\hline Tensão limite a compressão $\sigma_{\text {esm }}$ & 1 & 0,17 & 0,5 & 0,27 & 6,3 \\
\hline Módulo de cisalhamento $G_{L T}$ & 9 & 3,5 & 5,0 & 0,3 & 105 \\
\hline Tensão limite cisalhante $f_{\tau L T}$ & 1,15 & 0,14 & 0,6 & 108 & \\
\hline Coeficiente de dilatação térmica $\alpha, 10^{-6 \circ} \mathrm{C}^{-1}$ & & & 1,3 & & \\
\hline Coef. de absorção de água $\beta, \%$ em volume & & & 0,0354 & & \\
\hline Condutividade térmica a $37,5^{\circ} \mathrm{C}, \mathrm{W} / \mathrm{m}^{\circ} \mathrm{C}$ & & & 120 & & \\
\hline Temperatura máxima de serviço contínuo, ${ }^{\circ} \mathrm{C}$ & & & & \\
\hline
\end{tabular}

Obs.: tensões e módulos em MPa. Os valores de $G_{W T}$ e $f \square_{W T}$ são idênticos a $G_{L T}$ e $f \square_{L T}$ respectivamente.

Legenda:

$E_{T}$ - módulo de elasticidade na direção T;

$G_{L T}$ - módulo de cisalhamento no plano LT;

$G_{W T}$ - módulo de cisalhamento no plano WT do painel sanduíche, sendo $L$ e $W$ as direções principais do núcleo, que representam, respectivamente, os eixos x e y; logo, a direção T representará o eixo z, ou seja, a espessura do painel sanduíche.

Fonte: Allen (1969).

Quadro 1 - Propriedades termomecânicas típicas de espumas e plásticos expandidos e madeira do tipo balsa 


\begin{tabular}{l|l|l}
\hline & \multicolumn{1}{|c|}{ Norma } & \multicolumn{1}{c}{ Assunto } \\
\hline $\mathbf{1}$ & ASTM D1781-98 (2004) & $\begin{array}{l}\text { Deslocamento de adesivos (determinação da resistência ao } \\
\text { deslocamento normal de adesivos entre a face e o núcleo) }\end{array}$ \\
\hline $\mathbf{2}$ & ASTM C364/C364M-07 (2007) & Ensaio de compressão coplanar em sanduíche \\
\hline $\mathbf{3}$ & ASTM C393-00 (2000) & Ensaio de flexão em três e quatro pontos para sanduíche \\
\hline $\mathbf{4}$ & ASTM D3499-94 (2005a) & Tenacidade de compensados \\
\hline $\mathbf{5}$ & ASTM D3500-90 (2003) & Tração em painéis compensados estruturais \\
\hline $\mathbf{6}$ & ASTM D3501-05 (2005b) & Compressão em painéis compensados estruturais \\
\hline $\mathbf{7}$ & ASTM D3502-1976(1976a) & Absorção de umidade em produtos de madeira \\
\hline $\mathbf{8}$ & ASTM D3503-76 (1976b) & Efeito de dilatação higroscópica em produtos de madeira \\
\hline
\end{tabular}

Quadro 2 - Normas de ensaios aplicáveis a sanduíches estruturais

\begin{tabular}{|c|c|c|c|c|c|}
\hline Material & $E^{(\text {I) }} \mathbf{G P a}$ & $\sigma_{E}{ }^{(\text {II) }} \mathbf{M P a}$ & $\boldsymbol{v}^{(\mathrm{III})}$ & $\rho^{(\mathrm{IV})} \mathrm{kg} / \mathrm{m}^{3}$ & Aspectos gerais \\
\hline \multicolumn{6}{|l|}{ Alumínio $^{(\mathrm{V})}$} \\
\hline 1100-H14 & 70 & $90 c^{(\mathrm{VI})}$ & 0,33 & 2.710 & $\begin{array}{l}\text { custo médio, } \\
\text { resistência química }\end{array}$ \\
\hline 5052-H34 & 70 & $165 c$ & 0,33 & 2.710 & $\begin{array}{l}\text { custo médio, } \\
\text { resistência a } \\
\text { intempéries }\end{array}$ \\
\hline 6061-T6 & 70 & $240 \mathrm{c}, \mathrm{t}$ & 0,33 & 2.710 & soldável, trabalhável \\
\hline 2024-T3 & 72 & $300 t$ & 0,33 & 2.710 & $\begin{array}{l}\text { alta resistência, } \\
\text { resistência a } \\
\text { corrosão, temperável }\end{array}$ \\
\hline Aço carbono & 200 & 350 & 0,3 & 7.680 & baixo custo, pesado \\
\hline Inox 304 & 190 & 250 & 0,24 & 7.680 & $\begin{array}{l}\text { alto custo, } \\
\text { resistência a } \\
\text { corrosão }\end{array}$ \\
\hline $\begin{array}{l}\text { Woven grafite/epóxi } \\
\text { 282-F155 }\end{array}$ & 55 & 60 & 0,1 & 1.540 & \\
\hline $\begin{array}{c}\text { Fita grafite/epóxi } \\
\text { TXX145-F155 }\end{array}$ & 120 & 1.300 & 0,1 & 1.690 & alto custo, leve \\
\hline $\begin{array}{c}\text { Woven kevlar/epóxi } \\
\text { K49-285-F155 }\end{array}$ & 28 & $200 \mathrm{c}$ & $\approx 0$ & 1.400 & $\begin{array}{l}\text { leve, baixa } \\
\text { resistência a } \\
\text { compressão }\end{array}$ \\
\hline Fita kevlar/epóxi & 65 & $\begin{array}{l}1.100 \mathrm{t} \\
250 \mathrm{c}\end{array}$ & $\approx 0$ & 1.400 & custo médio \\
\hline Vidro/poliéster & 6,5 & 100 & 0,14 & 1.400 & custo bastante baixo \\
\hline $\begin{array}{l}\text { Vidro woven } \\
\text { roving/poliéster }\end{array}$ & 12 & 250 & 0,14 & 1.400 & custo bastante baixo \\
\hline $\begin{array}{c}\text { Woven glass/epóxi } \\
\text { 1581-F155 }\end{array}$ & 25 & 450 & 0,14 & 1.900 & $\begin{array}{l}\text { baixo custo, } \\
\text { resistente }\end{array}$ \\
\hline $\begin{array}{c}\text { Fita vidro/epóxi T25- } \\
\text { 285-F155 }\end{array}$ & 50 & 850 & 0,14 & & $\begin{array}{l}\text { custo médio, } \\
\text { resistente }\end{array}$ \\
\hline Compensado/pinho & 12 & 20 & 0,1 & 600 & baixo custo \\
\hline $\begin{array}{c}\text { Madeira endurecida e } \\
\text { temperada para } 1.000 \\
\mathrm{~kg} / \mathrm{m}^{3}\end{array}$ & 4,5 & 25 & 0,1 & 1.000 & baixo custo \\
\hline
\end{tabular}

Obs.: ${ }^{(\text {(I) }}$ Módulo de elasticidade; (II) Tensão de escoamento ou limite de ruptura; (III) Coeficiente de Poisson; ${ }^{\text {(IV) }}$ Densidade; (v) As espessuras de chapas de alumínio são normalizadas pela norma alemã DIN 1783 nos valores $0,4 / 0,5 / 0,6 / 0,8$ / $1,0 / 1,2 / 1,5 / 1,8 / 2,0 / 2,5 / 3,0 / 3,5 / 4,0 / 5,0 / 6,0 / 8,0 / 10,0 / 12,0 / 15,0$ mm; ${ }^{(\mathrm{Vl})} \mathrm{c}$ e $\mathrm{t}$ indicam valores a compressão e tração respectivamente.

Fonte: Mendonça (2005).

Quadro 3 - Propriedades de materiais tipicamente utilizados em faces de elementos do tipo sanduíche 
No Quadro 2 apresentam-se algumas das normas americanas ASTM (American Society for Testing and Materials) referentes aos ensaios em núcleos e painéis sanduíche.

O Quadro 3 apresenta as propriedades de alguns materiais utilizados em faces de elementos do tipo sanduíche.

\section{Critérios de falha e modos de falha}

O comportamento cinemático das estruturas sanduíche foi descrito baseando-se em formulações das teorias de placas laminadas. Segundo Mendonça (2005), o problema, para a análise, consiste em calcular a tensão de falha de uma lâmina ortotrópica submetida e um estado plano de tensões representado por $\left\{\sigma_{x}, \sigma_{y}, \tau_{x y}\right\}$, partindo de resistências obtidas de ensaios simples realizados em algumas poucas direções. As lâminas compostas possuem resistência a tração e a compressão diferentes, no entanto apresentam valores idênticos de resistência a cisalhamento, positivos ou negativos.

Para auxiliar na solução desse problema são utilizados os critérios de falha ou resistência. Estes têm por finalidade estabelecer leis pelas quais se pode, pelo comportamento do material nos ensaios de tração e de compressão simples, prever a condição de ruptura sob qualquer tipo de combinação de tensões, ou seja, um critério de resistência pretende interpretar os casos de solicitações combinadas, partindo apenas de um pequeno número de parâmetros do material. A grande variedade de materiais usados na engenharia não permite adotar um único critério.

De acordo com Jones (1975), Mendonça (2005) e Tita (2007), existem diversos modos de falha em estruturas sanduíche, sendo os mais característicos o escoamento ou ruptura das faces, cisalhamento no núcleo, flambagem global do painel, deslocamento excessivo, empenamento das faces (wrinkling), flambagem intracelular (dimpling) e esmagamento do núcleo.

\section{Projeto de estruturas sanduíche}

No projeto de uma estrutura sanduíche existem vários parâmetros a serem especificados pelo projetista. De modo simplificado, o projeto deve seguir duas etapas. No primeiro momento, as propriedades das faces e do núcleo são arbitradas e, em seguida, as espessuras de cada face e do núcleo são obtidas.

O desenvolvimento das teorias de vigas sanduíche baseou-se nas teorias de Euler-Bernoulli e de Timoshenko (TIMOSHENKO, 1985). A diferença básica entre esses modelos está relacionada ao fato de que a formulação de Euler-Bernoulli não considera a deformação de cisalhamento presente nas seções transversais, enquanto Timoshenko (1985) a considera. No caso de placas sanduíches, suas teorias se basearam nas teorias clássicas.

\section{Aplicação da teoria de flexão às vigas sanduíche}

A Figura 2 apresenta uma viga sanduíche, que consiste de duas faces finas de espessura $t$, separadas por um núcleo de material de baixa densidade e espessura $c$. A altura ou espessura total da viga é $h$; a largura, $b$; e o comprimento, $l$. As faces dessa viga são feitas de um material mais resistente que o do núcleo e considera-se que ambos sejam isotrópicos.

A teoria clássica da flexão considera que a seção transversal, que é plana e perpendicular ao eixo longitudinal quando a viga está descarregada, permanecerá assim após a flexão. Essa consideração leva à conhecida expressão que relaciona momento fletor $(\mathrm{M})$ e curvatura $\frac{1}{\omega}$.
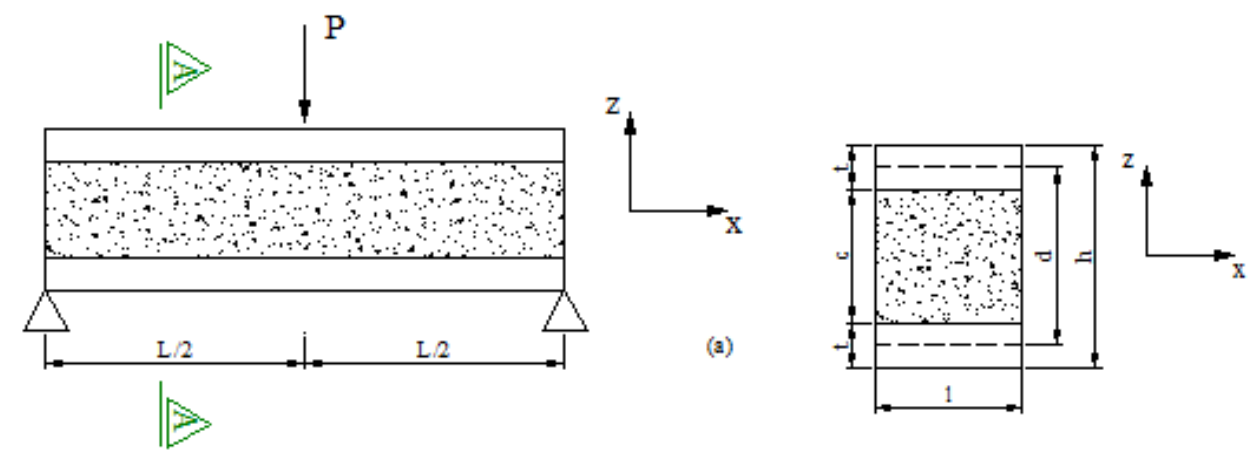

(b)

Figura 2 - Dimensões da viga sanduíche: (a) seção longitudinal, (b) seção transversal A-A 
$\frac{M}{E I}=-\frac{1}{\omega}$

Eq. 1

Onde:

\section{EI: rigidez à flexão (D);e}

$\omega$ : raio de curvatura.

O comportamento de uma viga sanduíche pode ser analisado, inicialmente, utilizando-se as teorias clássicas de vigas, desde que alguns cuidados sejam tomados. Segundo Allen (1969), existem dois cuidados:

(a) considerar as diferentes propriedades dos materiais, de forma clara; e

(b) considerar o efeito do cisalhamento transversal nos deslocamentos.

Portanto, deve-se usar a teoria de Timoshenko (1985) ou de uma ordem superior no trato do cisalhamento transversal.

Em uma viga sanduíche a rigidez a flexão é composta do somatório da rigidez a flexão das faces e a do núcleo, medidas a partir do eixo baricêntrico da seção transversal. Portanto:

$D=D_{\text {faces }}+D_{\text {núcleo }}$

$D=E_{f} \frac{b t^{3}}{6}+E_{f} \frac{b t d^{2}}{2}+E_{n} \frac{b c^{3}}{12}$

Eq. 2

Onde:

$D$ : rigidez a flexão;

$E_{f}$ : módulo de elasticidade das faces;

$E_{n}$ : módulo de elasticidade do núcleo; e

$d$ : distância entre as superfícies médias das faces.
Já as tensões normais nas faces e no núcleo podem ser determinadas utilizando-se a teoria clássica de flexão adaptada à natureza composta da seção transversal. A tensão normal nas faces é dada por:

$$
\begin{array}{ll}
\sigma_{f}=\frac{M E_{f} z}{D} \quad \frac{c}{2} \leq z \leq \frac{h}{2} ;-\frac{h}{2} \leq z \leq-\frac{c}{2} ; & \text { Eq. } 3 \\
\sigma_{n}=\frac{M z}{D} E_{n}-\frac{c}{2} \leq z \leq \frac{c}{2} & \text { Eq. } 4
\end{array}
$$

Ainda é necessário calcular a tensão de cisalhamento, que, após algumas simplificações, se reduz a:

$\tau=\frac{V}{b d}$

Eq. 5

Onde:

$b$ : largura;

$d:$ altura;

$I:$ momento de inércia; e

$V$ : cortante.

Pode-se notar que esta tensão é média e a condição $E_{n}=0$ (condição de simplificação) resulta também numa distribuição linear de tensões nas faces. Quando este estado de tensões é observado o núcleo pode ser dito com sendo antiplano, que é definido como aquele em que $\sigma_{\mathrm{x}}=\sigma_{\mathrm{y}}=\tau_{\mathrm{xy}}=0$. Neste caso não há contribuição do núcleo na rigidez à flexão do sanduíche.

Os deslocamentos transversais em vigas sanduíche podem ser calculados utilizando-se a teoria clássica de flexão de vigas (ver Figura 3). (a)

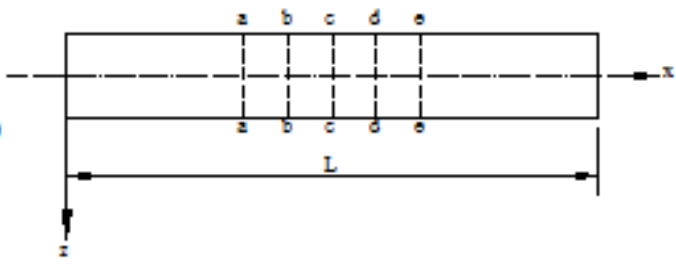

(b)

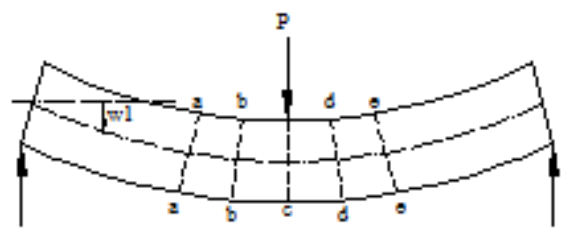

(c)

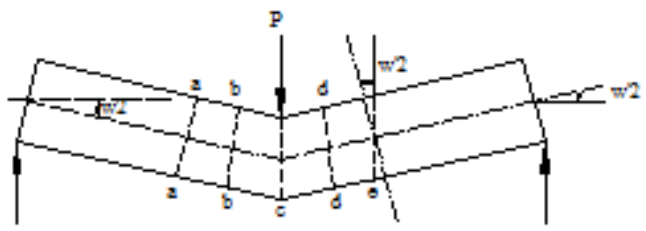

(d)

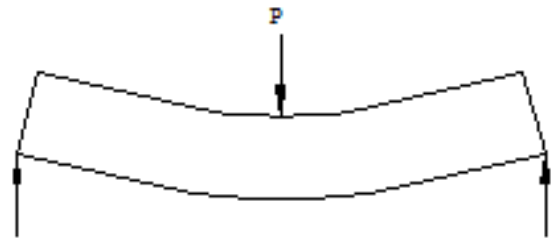

Figura 3 - Deslocamentos na viga sanduíche: (b) deslocamento devido à parcela de flexão pura; (c) deslocamento devido ao esforço cortante; e (d) deslocamento total 
O deslocamento total $w$ apresentado na Figura $3 \mathrm{~d}$ é a soma do deslocamento devido a flexão e o deslocamento devido a cisalhamento:

$$
w=w_{f}+w_{c}=\frac{P L^{3}}{48 D}+\frac{P L}{4 A G}
$$

\section{Aplicação da teoria de flexão às placas sanduíche}

Segundo Mendonça (2005), uma característica importante sobre o comportamento mecânico das placas sanduíche é que elas não podem, em geral, serem consideradas placas finas; ao contrário, elas são classificadas como placas semiespessas ou espessas, dependendo da relação $l / H$, na qual $l$ é o comprimento característico medido sobre a superfície, e $H$, sua espessura. Da mesma forma que em vigas sanduíche, os efeitos devidos ao cisalhamento não podem ser desconsiderados. Um dos efeitos do cisalhamento transversal pode ser visto quando se considera qualitativamente o deslocamento transversal de uma placa sanduíche, como visto na Figura 4.

Além da importância de se incluir o cisalhamento no cálculo de placas sanduíche, existe outro a ser considerado: os materiais usados como núcleo são selecionados para serem os mais leves possíveis e, consequentemente, têm resistências ao cisalhamento muito menores que os materiais usados nas faces, tornando importante a correta determinação das tensões cisalhantes transversais.
A análise do laminado deve, então, garantir a integridade do núcleo quanto ao cisalhamento.

Em etapa de pré-cálculo, em vez de se usarem os valores dados pela matriz de rigidez à flexão, segundo Allen (1969), pode-se usar uma aproximação obtida pela teoria da resistência dos materiais.

Para faces isotrópicas de mesmo material e espessuras distintas, tem-se:

$$
\begin{aligned}
& D_{x}=\frac{E_{f} t_{1} t_{2} d^{2}}{\left(t_{1}+t_{2}\right)}, \\
& \lambda=1-\left(v^{f}\right)^{2}
\end{aligned}
$$

Para faces isotrópicas de material e espessuras idênticas,

$D_{x}=\frac{E_{f} t d^{2}}{2 \lambda}$

Onde:

$D_{\mathrm{x}}$ : rigidez à flexão; e

$E_{f}$ : módulo de elasticidade da face.

Em geral, os problemas que envolvem placas são possíveis de serem resolvidos através de séries de funções ou de forma numérica, como pelo Método dos Elementos Finitos.

Na Figura 5 está apresentada uma placa retangular com dimensões e eixos definidos, na qual se pode observar que $L$ e $W$ são as direções principais do núcleo.

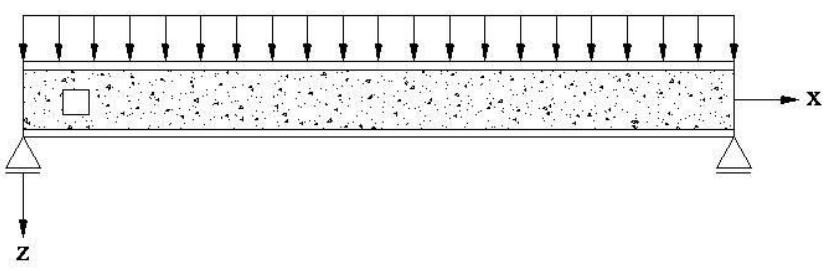

(a)

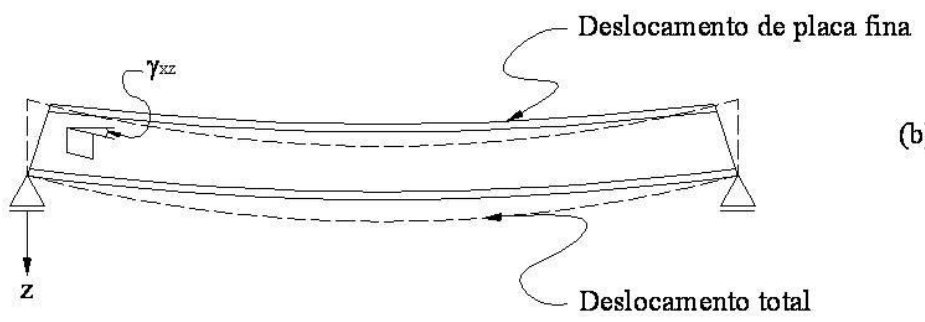

Figura 4 - Comparação quantitativa entre os deslocamentos obtidos em placas sanduíche usando teorias de placa fina e semiespessa 


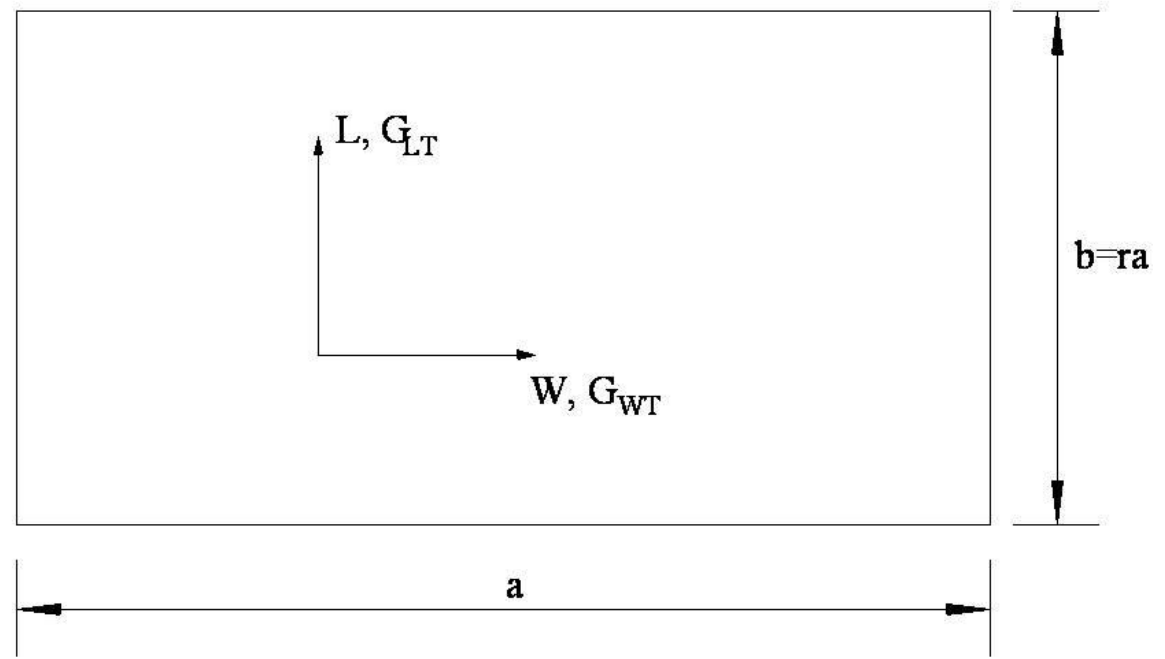

Figura 5 - Nomenclatura usada na solução da placa sanduíche retangular

De acordo com Mendonça (2005), as funções a seguir permitem o cálculo de deslocamentos e tensões em alguns pontos da placa.

O deslocamento máximo é dado por:

$w_{\text {máx }}=K_{1} \frac{2 q_{0} b^{4} \lambda}{E^{f} t d^{2}}$

A tensão normal máxima na face é dada por:

$\sigma_{\text {máx }}=K_{2} \frac{q_{0} b^{2}}{t d}$

A tensão cisalhante no núcleo no meio da borda de comprimento $b$ é:

$\tau_{b}=K_{3} \frac{q_{0} b}{d}$

E a tensão cisalhante no núcleo no meio da borda de comprimento $a$ é:

$\tau_{a}=K_{4} \frac{q_{0} b}{d}$

Eq. 12

As constantes $K_{l}, \quad K_{2}, \quad K_{3}$ e $K_{4}$, constantes adimensionais, dependem dos seguintes parâmetros:

$r=\frac{b}{a} ; f_{\tau}=\frac{G_{L T}}{G_{W T}} ; \quad V=\frac{\pi^{2} D}{b^{2} d G_{W T}}$

Considerando:

$L$ e $W$ notações usadas em núcleos de colmeia;

$D$ : rigidez à flexão do painel; e

$G_{L T}$ e $G_{W T}$ : os módulos de elasticidade cisalhantes transversais do núcleo.
Com base nesses parâmetros, essas constantes foram calculadas.

\section{Rotina de cálculo para estruturas sanduíche}

Para facilitar a elaboração de projetos em estruturas sanduíche, Allen (1969) e Mendonça (2005) apresentam um roteiro das principais etapas no processo de projeto de vigas e placas sanduíche retangulares.

\section{$1^{\text {a }}$ etapa: definição do tipo estrutural}

No caso de a estrutura ser apoiada apenas por duas faces opostas, deve-se decidir se esta será analisada como viga ou placa. Para tanto, utilizamse as seguintes relações de placas isotrópicas:

$\frac{b}{a} \leq \approx 0,3 \rightarrow$ comportamento de viga; $\mathrm{e}$

$\frac{b}{a} \geq \approx 0,8 \rightarrow$ placa infinita sob flexão cilíndrica.

Sendo $a$ comprimento do painel e $b$ altura do painel. Caso os componentes sejam apoiados por mais de duas bordas, devem ser analisados sempre como placas.

\section{$2^{\text {a }}$ etapa: identificação dos carregamentos}

Deve-se identificar os carregamentos que estão sendo aplicados à estrutura e procurar uma adaptação dos carregamentos aos tipos disponíveis nas ferramentas simplificadas de cálculo. Carregamentos mais complexos, próximos da 
situação real, ficam para as próximas etapas de análise, com o uso do método de elementos finitos.

\section{$3^{\mathrm{a}}$ etapa: definição dos materiais das faces e do núcleo}

Verifica-se quais os materiais disponíveis para serem utilizados na estrutura.

\section{$4^{\text {a }}$ etapa: identificação das propriedades elásticas e de resistência}

Os seguintes procedimentos devem ser realizados:

(a) identificar as propriedades elásticas nas faces:

$E_{x}$ módulo de elasticidade na direção $x$, e $v_{x y}$

coeficiente de Poisson no plano $x y$; em alguns casos deve-se partir de um valor estimado para o início dos cálculos;

(b) identificar $E_{x}, E_{y}, E_{x y}, G_{x z}$ e $G_{y z}$ do núcleo. Deve-se utilizar os dados dos fabricantes ou os dados tabelados em pesquisas acadêmicas, como Gagliardo (2008);

(c) identificar as resistências a tração e compressão na direção $x$ e na direção $y$ para as faces. Já para o núcleo deve-se identificar as tensões resistentes de cisalhamento transversal; e

(d) identificar o deslocamento máximo admissível, $W_{z}$, para o painel sanduíche.

\section{$5^{\text {a }}$ etapa: definição das espessuras}

$\mathrm{O}$ procedimento consiste em definir as espessuras das faces e do núcleo. Caso o núcleo escolhido seja o colmeia, é necessário identificar a largura da célula e a espessura da chapa de colmeia (utilizar dados do fabricante).

\section{$6^{\text {a }}$ etapa: verificação das dimensões das faces}

Após a definição de espessuras e propriedades, pode-se verificar a possibilidade de usar as hipóteses de sanduíche de faces delgadas com núcleo antiplano.

\section{$7^{\mathrm{a}}$ etapa: verificação da tensão normal de flexão nas faces}

Cálculo utilizando as formulações expostas neste trabalho para vigas ou placas.

\section{$8^{\text {a }}$ etapa: verificação da tensão cisalhante no núcleo}

Como na etapa anterior, utilizam-se as formulações de cisalhamento para essa verificação.

\section{$9^{\text {a }}$ etapa: verificação dos deslocamentos}

Nesse momento faz-se uma comparação com o deslocamento admissível. Frequentemente se utiliza como deslocamento máximo o valor $W_{z}=$ 1/300. Dependendo da norma, em alguns casos, o limite é ainda mais rigoroso e passa a ser $W_{z}=$ $l / 600$, sendo $l$ um comprimento característico, geralmente a distância entre apoios.

\section{Aplicação da planilha de cálculo}

Com base na pesquisa desenvolvida e após uma análise crítica das teorias envolvendo as estruturas sanduíche, consequentemente, chegou-se à rotina de cálculo descrita anteriormente, gerando-se uma ferramenta computacional para auxiliar os projetistas no processo de cálculo envolvendo estruturas sanduíche, já que são necessárias algumas repetições para obter-se a seção ótima dessa estrutura. Essa planilha foi desenvolvida com o auxílio do software Microsoft Excel.

Para a utilização dessa ferramenta o projetista deverá ter definido os dados das faces, do núcleo e os gerais. Na sequência a planilha realiza os cálculos necessários, resultando desse processamento inicial as espessuras das faces e do núcleo, considerando as teorias e constantes de cálculo vistas anteriormente.

Os resultados gerados devem ser analisados e, em seguida, o calculista define quais serão as espessuras adotadas para as faces e o núcleo.

Entrando com os valores das espessuras adotadas, a planilha efetuará as verificações de segurança referentes às teorias das estruturas sanduíche. Se as verificações resultarem em situações de segurança ótima, o cálculo termina e a placa sanduíche está projetada; caso contrário, basta redefinir as espessuras adotadas, e o processo de cálculo da planilha será repetido.

Por se tratar de um processo iterativo, este último passo pode ser refeito quantas vezes forem necessárias, até obter-se uma seção ótima para a estrutura sanduíche.

\section{Avaliação da rotina de cálculo com diferentes materiais}

A seguir apresentam-se alguns casos calculados e comparados utilizando-se a planilha eletrônica desenvolvida nesta pesquisa.

\section{Caso 1}

Tem-se um vão $a \times b=3,0 m \times 1,0 m$, que se espera vencer com uma placa sanduíche simplesmente apoiada, submetida a uma carga uniformemente 
distribuída $q_{0}=0,001 \mathrm{~N} / \mathrm{mm}^{2}$. O material para a confecção da face será alumínio 5052. Para efeito comparativo serão modificados os materiais do núcleo:
(a) núcleo em poliestireno expandido;
(b) núcleo em poliuretano;
(c) núcleo em PVC;
(d) núcleo em balsa; e
(e) núcleo em fenólicos.

\section{Solução}

As propriedades dos núcleos são obtidas através dos Quadros 1 e 3. Seguindo a rotina de cálculo e utilizando-se a ferramenta eletrônica criada para auxiliar o projetista no processo de definição do painel sanduíche a ser utilizado em cada construção, os dados obtidos nos quadros foram introduzidos na planilha de cálculo, que já efetuou as verificações de segurança estrutural $\left(6^{\mathrm{a}}\right.$ a $9^{\mathrm{a}}$ etapa da rotina de cálculo). Os resultados obtidos para as dimensões das faces e núcleos, através dessas análises, podem ser observados na Figura 6.

Para essa placa sanduíche pode-se observar que, apesar das mudanças do material do núcleo e suas espessuras, as espessuras das faces não sofreram nenhuma alteração. Também é possível verificar através do gráfico apresentado na Figura 6 que a massa total da placa possui certa variação e que esta não está relacionada com a espessura total da estrutura.

Neste caso, a placa com menor densidade foi a com núcleo de poliuretano e a com maior densidade a com núcleo de poliestireno expandido, para resistirem à mesma carga distribuída.

\section{Caso 2}

Tem-se um vão de $a \times b=3,0 m \times 1,0 m$, que se espera vencer com uma placa sanduíche simplesmente apoiada, submetida a uma carga uniformemente distribuída $q_{0}=0,001 \mathrm{~N} / \mathrm{mm}^{2}$. O material para a confecção do núcleo será poliestireno expandido. Para efeito comparativo serão modificados os materiais das faces:
(a) face em alumínio 5052;
(b) face em aço carbono;
(c) face em woven glass/epoxy 1581 - F155;
(d) face em compensado/pinho; e
(e) face em inox 304 .

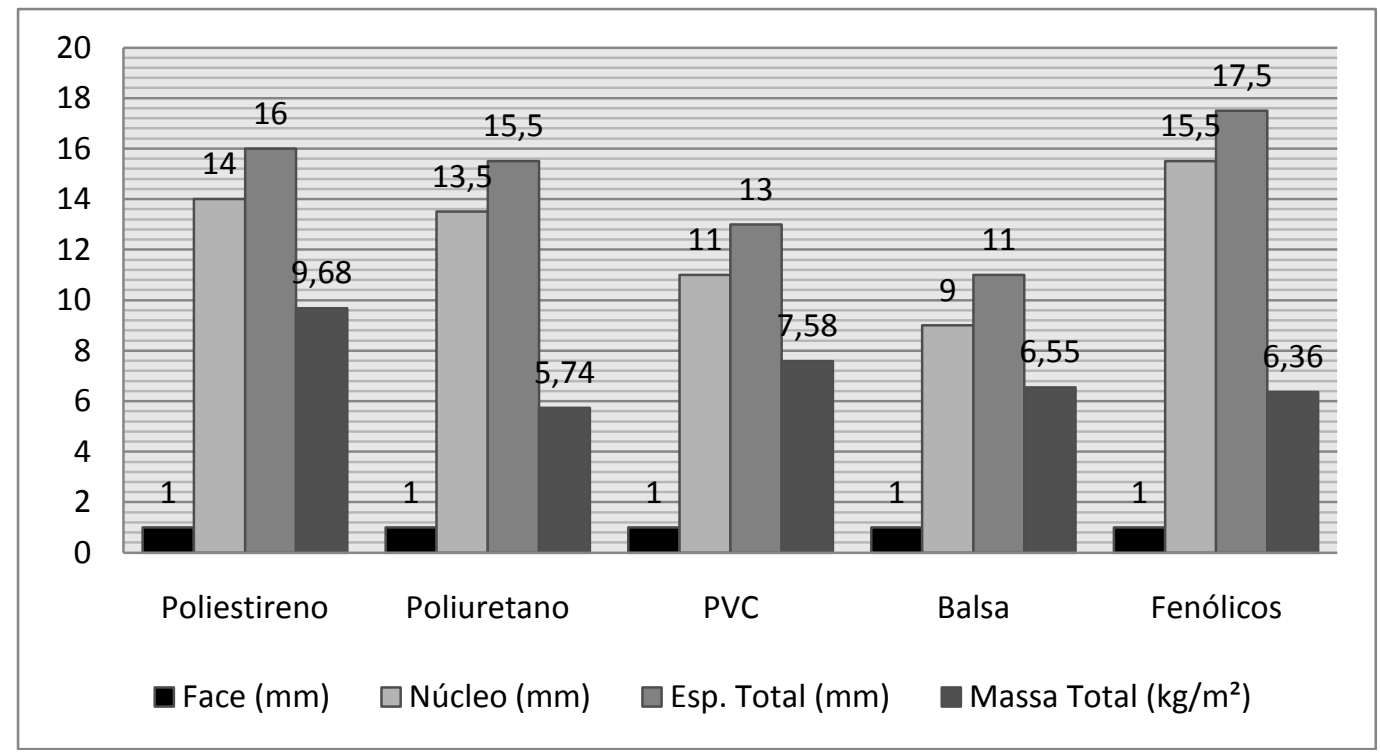

Figura 6 - Gráfico comparativo: face em alumínio 5052 


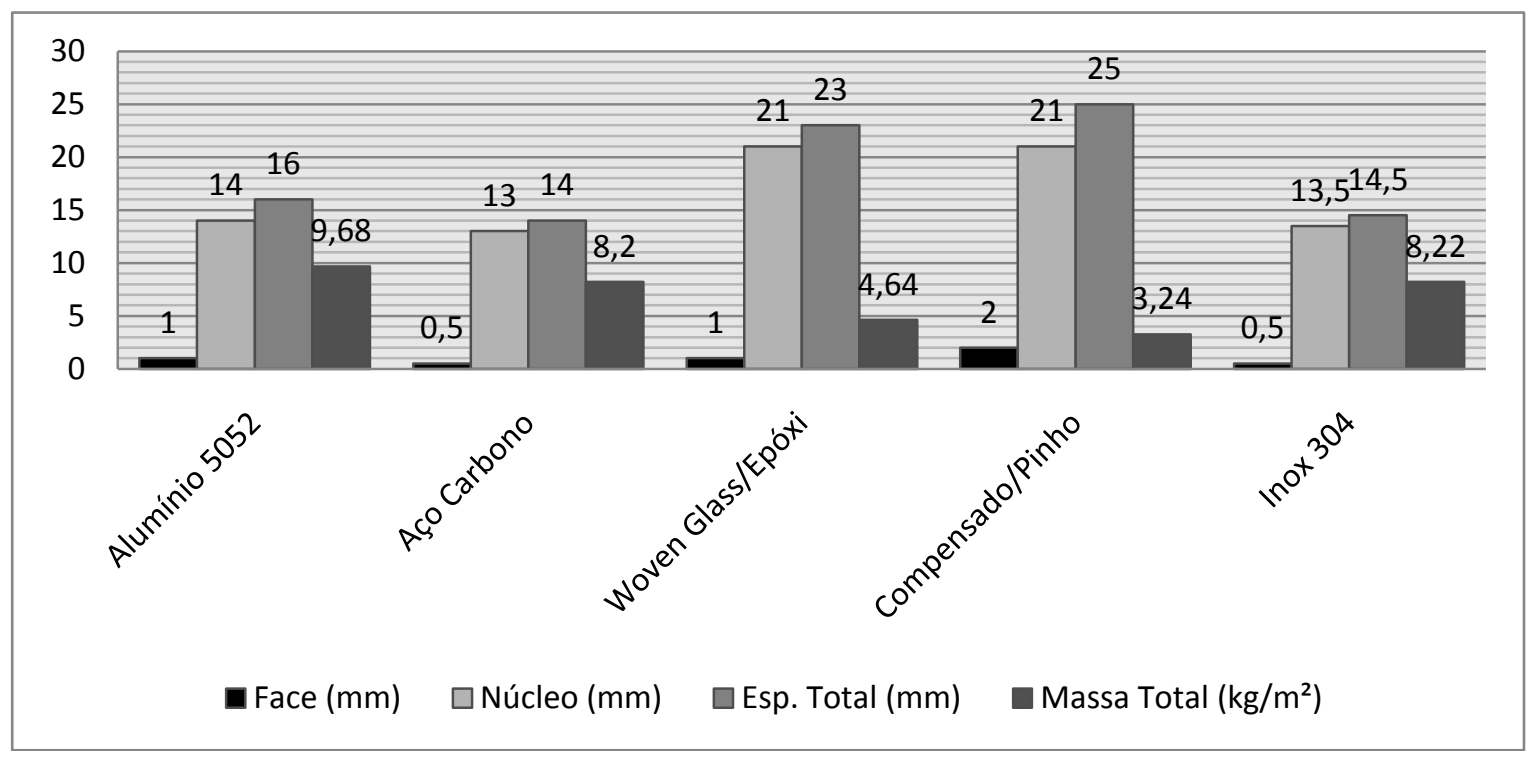

Figura 7 - Gráfico comparativo: núcleo em poliestireno expandido

\section{Solução}

As propriedades dos núcleos são obtidas nos Quadros 1 e 3. Seguindo a rotina de cálculo e utilizando-se a ferramenta eletrônica criada para auxiliar o projetista no processo de definição do painel sanduíche a ser utilizado em cada construção, os dados obtidos nos quadros foram introduzidos na planilha de cálculo, que já efetuou as verificações de segurança estrutural $\left(6^{\mathrm{a}}\right.$ a $9^{\mathrm{a}}$ etapa da rotina de cálculo). Os resultados obtidos para as dimensões das faces e núcleos, através dessas análises, podem ser observados na Figura 7.

Para essa placa sanduíche fixou-se o material do núcleo, fato que gerou uma grande variação nas espessuras totais das peças (gráfico da Figura 7), pois tanto as faces quanto os núcleos sofreram alterações de espessura para vencer o vão determinado com o carregamento empregado na estrutura. Ainda observando o gráfico acima, podese verificar a variação das massas totais, sendo a peça com menor massa a que apresenta a maior espessura total.

Se o critério do projeto for a diminuição da densidade, deve-se utilizar a placa com faces em compensado/pinho e núcleo em poliestireno, com espessura total de $25 \mathrm{~mm}$ e massa de $3,24 \mathrm{~kg} / \mathrm{m}^{2}$.

\section{Considerações finais}

Ao se projetar utilizando estruturas sanduíche, deve-se ter em mente que se está associando propriedades de dois materiais distintos para se melhorarem as características mecânicas da estrutura. Nesse momento, o projetista deve definir se o cálculo será feito considerando a teoria de vigas ou de placas, e também nesse momento são definidos os materiais a serem empregados na confecção do painel sanduíche.

Através dessa análise mecânica, estrutural, formulou-se uma rotina de cálculo, sistematizando os dados e equações referentes às estruturas, para facilitar a execução dos projetos. A montagem de uma planilha eletrônica para auxiliar nos cálculos contribuiu de forma positiva, pois as verificações se tornaram mais ágeis e fáceis de serem feitas, o que possibilitou a realização de diversas verificações com os dados fornecidos para as propriedades dos materiais, bastando ao projetista especificar as espessuras das faces e núcleo. A realização de comparativos permitiu a verificação das melhores opções para a confecção dos painéis sanduíche.

\section{Referências}

\section{ALLEN, H. G. Analysis and Design of}

Structural Sandwich Panels. Hungary: Pergamon Press, 1969.

AMERICAN SOCIETY FOR TESTING AND
MATERIALS. ASTM Standard C364/C364M-

07: standard test method for edgewise compressive strength of sandwich constructions. West Conshohocken, PA, 2007.

\section{AMERICAN SOCIETY FOR TESTING AND}

MATERIALS. ASTM Standard C393-00:

standard test method for flexural properties of sandwich constructions. West Conshohocken, PA, 2000 . 
AMERICAN SOCIETY FOR TESTING AND MATERIALS. ASTM Standard D695-02a: standard test method for compressive properties of rigid plastics. West Conshohocken, PA, 2002.

AMERICAN SOCIETY FOR TESTING AND MATERIALS. ASTM Standard D1781-98: standard test method for climbing drum peel for adhesives. West Conshohocken, PA, 2004.

AMERICAN SOCIETY FOR TESTING AND MATERIALS. ASTM Standard D3499-94: standard test method for toughness of wood based structural panels West Conshohocken, PA, 2005.

\section{AMERICAN SOCIETY FOR TESTING AND}

MATERIALS. ASTM Standard D3500-90: standard test methods for structural panels in tension. West Conshohocken, PA, 2003.

AMERICAN SOCIETY FOR TESTING AND MATERIALS. ASTM Standard D3501-05a: standard test methods for wood based structural panels in compression. West Conshohocken, PA, 2005.

AMERICAN SOCIETY FOR TESTING AND MATERIALS. ASTM Standard D3502-76:

Moisture absorption of compressed wood products. EUA: ASTM, 1976.
AMERICAN SOCIETY FOR TESTING AND

MATERIALS. ASTM Standard D3503-76:

swelling and recovery of compressed wood products due to moisture absorption. West Conshohocken, PA, 1976.

CALlister JÚNIOR, W. D. Ciência e

Engenharia de Materiais: uma introdução. 5. ed. Rio de Janeiro: LTC, 2002.

GAGLIARDO, D. P. Análise de Estruturas Sanduíche: parâmetros de projeto. 2008.174 f. Dissertação (Mestrado em Estruturas) - Faculdade de Engenharia Civil, Arquitetura e Urbanismo, Universidade Estadual de Campinas, Campinas, 2008.

JONES, R. M. Mechanics of Composite

Materials. Tokyo: McGraw-Hill Kogakusha, 1975.

MENDONÇA, P. T. R. Materiais Compostos \& Estruturas-Sanduíche: projeto e análise. Barueri, SP: Manole, 2005.

TIMOSHENKO, S. Resistência dos Materiais. Rio de Janeiro: LTC, 1985.

TITA, V. Projeto e Fabricação de Estruturas em Material Compósito Polimérico. Notas de aula. Universidade de São Paulo,Faculdade de Engenharia Mecânica, 2007. 68 p. 